\title{
MARKETING RETIREMENT HOUSING AS ASPIRATIONAL AND NOT A SIGN OF CRISIS
}

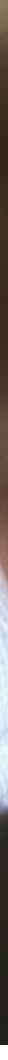

LOUISE DREW,

PARTNER \& HEAD OF BUILDING COMMUNITIES, SHAKESPEARE MARTINEAU 


\section{Executive Summary}

We conducted consumer research with more than 2,000 adults and more than 100 representatives from retirement housing providers from across the UK to identify the 'perception gap' and gathered high-profile representatives from across the retirement housing sector to discuss the data.

- Our research shows that the public are unsure about the benefits and services provided by retirement housing schemes - often confusing them with care homes and nursing homes to the detriment of the sector

- We identify an untapped referrer market for retirement living, that men should be targeted with entry-level information and people should be targeted before retirement age when perceptions are less 'fixed'

- We show the services that matter most to ABC1 demographic and the sources they use to find information

- We outline how the sector can make retirement housing a model of 'want' instead of a model of 'need'.

Emerald Group Publishing Limited

Howard House, Wagon Lane

Bingley BD16 1WA, United Kingdom

$\mathbf{T}+44(0) 1274777700$

$\mathbf{F}+44(0) 1274785201$

E emerald@emeraldinsight.com 


\section{Introduction}

It's estimated substandard housing costs the NHS E1.4billion annually - unsuitable housing is exacerbating poor physical and mental health. But, despite the availability of retirement housing stock that could delay the need for entering residential care (costing the state and families between $£ 27,000$ and $£ 55,000$ annually) there is hesitancy from the public to move from family homes that do not appropriately meet their needs.

Our argument is that more must be done by the sector and government to target people earlier and improve perception of retirement living, to benefit residents, the NHS and increase the number of family homes available, thus improving the housing crisis.

\section{Findings}

Our findings are arranged in distinct themes: perception, benefits understanding, who to target, influencing factors, how to target and language.

\section{Perception}

Public perception of retirement housing was skewed almost 1 in 3 public respondents think an 'Old People's Home' is synonymous with retirement housing and 1 in 5 equate them with nursing homes. This misconception is tarnishing the reputation of retirement housing - only worsened by high mortality rates of residents during the COVID-19 pandemic.
Terms Public Recognise

Terms Providers Use
Figure 1 shows the results in percentages after the public and providers were asked which, if any, of the following words or phrases do yo think best describe a retirement housing scheme?

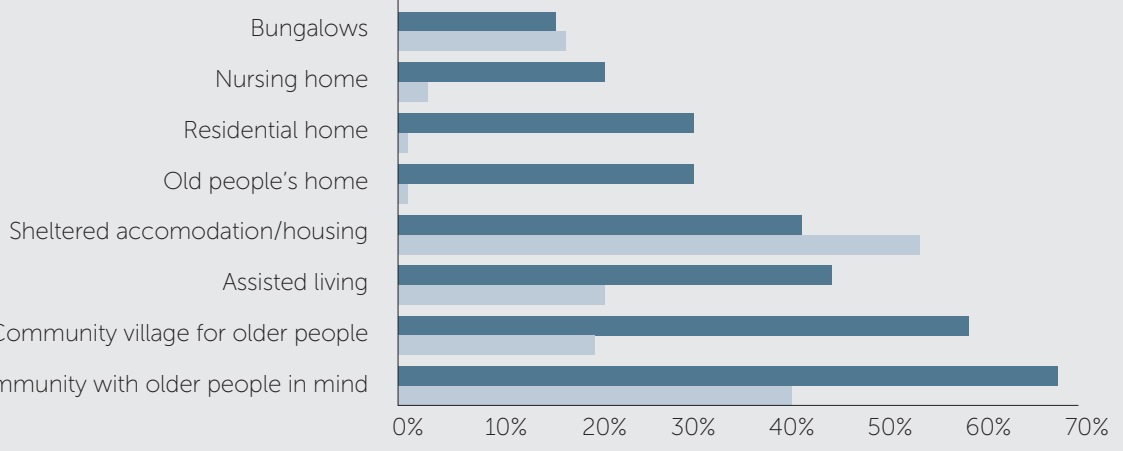

Figure 1

Purpose-built community with older people in mind

\section{Benefits understanding}

When asked about the type of people who would benefit from retirement housing, the public generally reinforced the stereotype of a 'lonely, single older person with health issues'. The majority (more than 50\%) of housing providers selected almost every category option in Figure 2 below (with the exception of 'older people who want to live in a mixed age community', which achieved 45\%). In contrast, the public generally did not believe that highly active or working older people would benefit from a retirement housing scheme. Interestingly, housing providers believe older couples are amongst the most suitable group (91\%) but only $44 \%$ of the public agree who believe they are more suitable for single people $(67 \%)$.

Figure 2 shows the results in percentages after the public and provides were asked 'which people, if any, would benefit from living in a retirement housing scheme?

Older people who are working

Older people who want to live in a mixed age community

Older people with dementia

Older people who are highly active and independent

Older couples

Older people with physical disabilities

Older people looking to downsize

Older people who feel vulnerable because of health issues

Single older peopke

Older people who want to live near people of a similar age

Figure 2

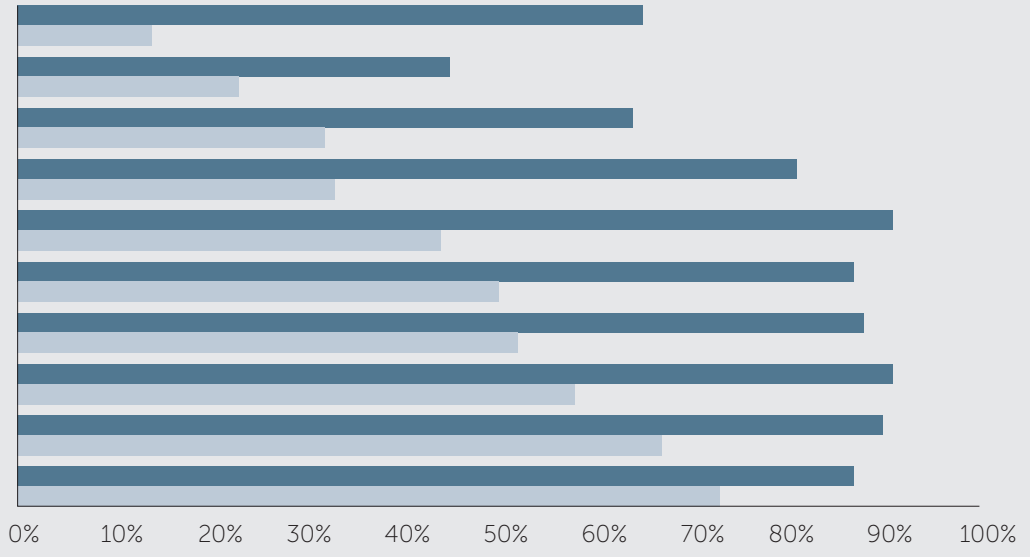

Regarding the benefits of schemes the public were most confident that retirement housing offered a safe and secure place to live $(76 \%)$, that they are a good alternative to residential care homes $(66 \%)$ and they offer a desirable place to live (62\%). However only $28 \%$ of the public agree that retirement housing offers good value for money - with nearly half of respondents stating that they didn't know. These data are shown in Figure 3 below. 
Figure 3 shows the results in percentages after the public were asked to what extent they agreed or disagree with several benefits statements of retirement housing schemes.

$$
\begin{aligned}
& \text { Agree } \\
& \text { Disagree } \\
& \text { Don't Know }
\end{aligned}
$$

Offer a desireable place to live

Offer good value for money

Offer high quality accomodation and services

Offer a safe and secure plave to live

Are a good alternative to residential care homes

There are not enough good quality RHS's near to where I live
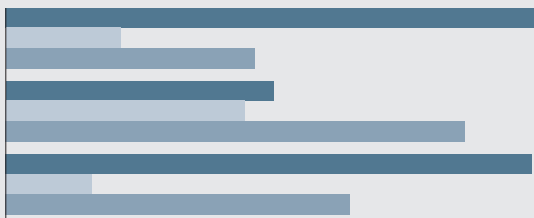

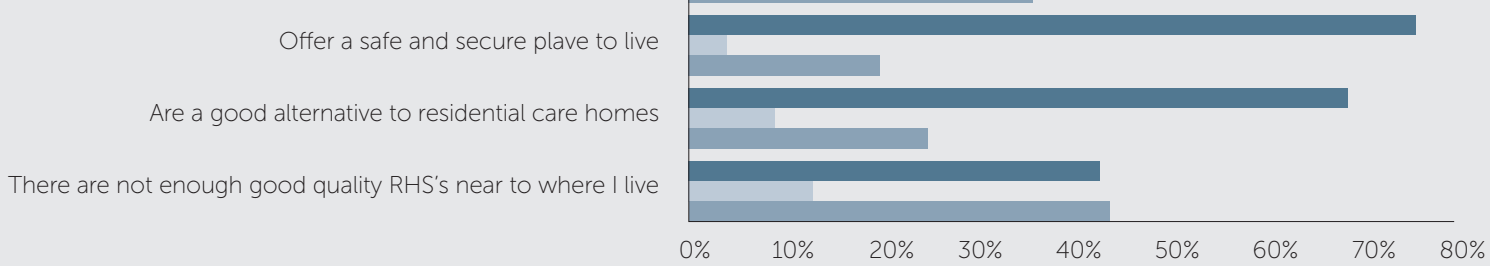

\section{Who to target}

When asked if they would consider moving into a retirement housing scheme themselves, public respondents were unsure - only $8 \%$ saying they would 'definitely' consider moving in. More than 3 in 4 people responded with either 'maybe' or 'don't know'.

An even greater proportion of public respondents were undecided on whether they would recommend retirement housing schemes to others - with 79\% opting for 'maybe' or 'don't know', posing the argument that there is also an untapped referral market who could be convinced to recommend retirement housing schemes to friends and family members if they had the right information.

The research also indicated opportunities to increase the knowledge of men and younger people approaching middle age, who statistically showed less understanding of the sector services and benefits. Earlier education of the benefits could lead to adoption later on, as well as influencing the all-important referrer market highlighted in our research.

If we focus in on responses of those approaching and in middle age (45 years and over) of what would encourage them to move into retirement housing schemes, we see an interesting shift in opinion between 45 years and 55 years and over among this cohort. (See figure 4)

\section{Influencing factors}

We wanted to know what factors might encourage people to move into a retirement housing scheme. The top performing factors - achieving more than $85 \%$ selection - were 'if the scheme was local to where their family currently live', 'if the scheme offered additional care or support for their needs', 'if they were lonely and wanted more company', 'if their current property was no longer suitable for them'. Ultimately, care and location is what currently matters to the public.

When we delve into the data further we see slight differences between the priorities of those identified to be ABC1 demographic against C2DE demographic. Transport links were important factors to nearly half (49\%) of $A B C 1$, but less than 2 in 5 (39\%) in the C2DE demographic. Care and support was also more important to ABC1 achieving $54 \%$ selection, compared to $42 \%$ selection by C2DE. What all demographics agreed on however, was 'if the scheme was local to where my family currently live' and whether the 'scheme was more affordable than where I am currently living'.

\section{Don't know what would encourage me to move into a RHS}

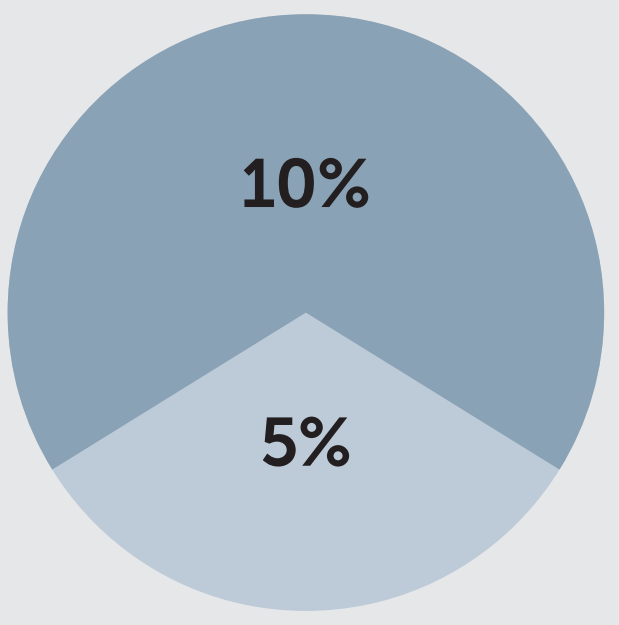

$45-54$

$55+$

\section{encourage me to move into a RHS}

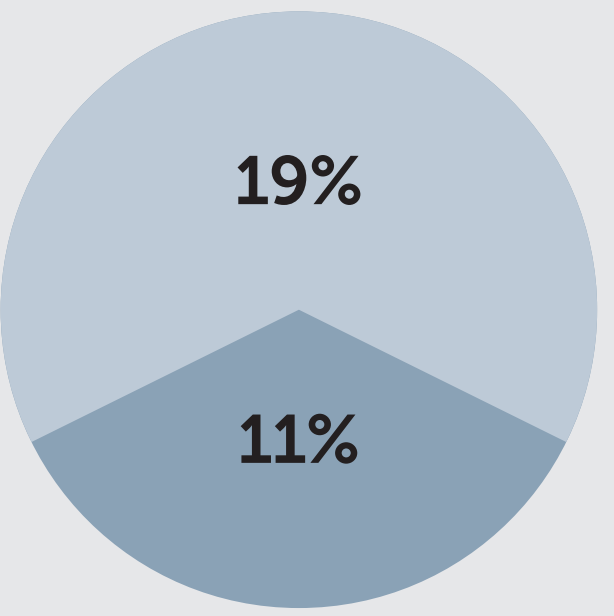

$45-54$
$55+$ 


\section{How to target}

When asked where they would look for information about retirement housing schemes the most popular choice was an internet search (71\% total average) - however, this result was much higher for ABC1 demographic at $79 \%$, compared to just 60\% C2DE. Almost 1 in 5 (18\%) of C2DE category said they didn't know where to get the information from. Following general internet search the most likely place the public would search is the government or local authority website - showing the need for a more consistent approach to centralised information and resources online for older people.

Just 1 in 4 would turn to friends or family - indicating a need to have clear information online is likely to be the most effective form of communication, preferably led by government, to build trust and understanding with the public.

\section{Language}

When we offered housing providers an open text box to list descriptors for retirement housing, 10 additional terms were produced; from Extracare and independent living to sheltered housing and retirement community, with so many terms used by the sector, how can the public understand what the product is?

\section{Implications}

- Demystify public perception that retirement housing is synonymous with 'old people's homes' and 'care homes' by opening schemes to the public

- Make scheme descriptions more inclusive and benefitsled - not exclusive to 'older people'

- Provide greater cost transparency

- Focus marketing and education on the important influencing factors for the target demographic considering affluence, and location and target people pre-retirement

- Target men at an introductory level and target women with more detail to strengthen knowledge and association of benefits

- Consider the importance of the potential referral market

- Use online platforms as a primary platform for information

- Create an advisory board for older people - with national website

\section{Recommendations: A model of want not need}

The issue of ageism when referring to housing, stems from historic retirement housing schemes that were built on a dependency model, with little to no aspirational contributory factors. Experts agreed that it was up to the sector to sell not allocate homes in the retirement housing schemes.

While retirement housing schemes are typically built with 'older people' in mind - they are not exclusive to these individuals and may be suitable for other members of the community who could benefit from the schemes, such as those with a disability, indicating schemes should be promoted according to their benefits and not simply for people past a certain age.

The sector should be honest with itself about affordability and quality - addressing the costs, profiling and services, giving clarity on what the product is and who it is for. With so many different models it will be impossible to capture retirement housing in a single term, but taking a positive approach; identifying the benefits, telling stories that bring these benefits to life and providers committing to delivering these standards, the sector can finally stamp out the misunderstanding and confusion between retirement housing and care homes.

\section{Contact details}

Louise Drew, Partner \& Head of Building Communities, louise.drew ashma.co.uk 


\section{References}

Inquiry into decent and accessible homes for older people (2019) https://www.ageuk.org.uk/globalassets/ age-uk/documents/reports-and-publications/appg/appg-for-ageing-and-older-people---report-on-decent-andaccessible-homes-for-older-people.pdf

Money Helper (2021) Care home or home care? https://www. moneyadviceservice.org.uk/en/articles/carehome-or-home-care

Shakespeare Martineau (2021) https://www.shma.co.uk/retirement-housing-white-paper/

Daly, M. (2020) COVID-19 and care homes in England: What happened and why?, Social Policy \& Administration, Volume 54, Issue 7, p. 985-998 https://onlinelibrary.wiley.com/doi/full/10.1111/spol.12645 